\title{
Projecting Movement, Union, Synergy, Interplay \& Cultural-collaboration across the Silk Road (\& beyond)
}

\author{
Chuah Aaron \\ global citizen
}

Aim

Interplay between culture and globalisation, and in particular the musical connection between the two has been forwarded as an illustrative, hopeful, and harmonious example of how humanity as a global race may enhance mutual understanding and cross-cultural appreciation of its many diverse groups. In particular, this study aims to investigate the global community-building behind the relatively recent Silkroad initiative, and to what degree has its aims been achieved, and how.

\section{Introduction}

The dawn of globalisation (though the term was only coined probably in the 1930s, ${ }^{1}$ and popularised in the mid-1980s 2 ), probably began at the confluence of the traditional "East" and "West" thousands of years ago, along what is now popularly known as the "Silk Road" or "Silk Route", a slight misnomer for it was not a single lengthy road but an ancient network of caravan and maritime routes stretching from Japan and the Korean peninsula in far east Asia to the Mediterranean Sea in the near west, through which it also linked the European and African continents. So named because of its distinct trade of silk amongst other items, particularly horses and spices, the Silk Road has been a channel of exchange between great civilizations from antiquity including the Persians, Syrians, Arabs, Turks, Arabs, Indians and Chinese.

The first documented Silk Road crossing ${ }^{3}$ was led by emissary Zhang Qian (Chang Ch'ien / K'ien) in 139 BCE under the remit of Han Chinese emperor Wu-Di who wished to explore the possibility of alliance with their Central-Asian enemies, which led to deep interest in establishing and defending this trade route. Over a period of twenty years including more than a decade in captivity by enemy forces, Zhang led two expeditions from Chinese imperial capital Chang'an (modern-day Xi'an) to Sogdia, an ancient Iranian civilisation that covered modern Samarkand and Bukhara, from which he chronicled ${ }^{4}$ reports of the surrounding regions including Mesopotamia by the "Western Sea" (the Mediterranean). ${ }^{5}$

\footnotetext{
${ }^{1}$ (Sadler, 1930)

2 (Levitt, 1960)

${ }^{3}$ (Twitchett, Fairbank, \& Loewe, 1978, pp. 163-165)

${ }^{4}$ (Qian, 1993)

5 (Hays, 2017)
} 
Movement of people, brought along with it language, culture, diversity, and since the primary purpose of these routes was to facilitate trade (rather than territorial conquest), along each step of the way, alongside the bartering of goods, came a natural need and desire to exchange ideas, languages, cultures, and invariably, musics.

This study aims to explore the musical and synergistic aspects of these cultural collaborations, encapsulated in a modern case study of the appropriately-named Silk Road Project and its eclectic innovative Ensemble.

\section{The Silk Road Ensemble}

Inspired by the rich breadth of tradition and culture along the Silk Road, renowned cellist Yo-yo Ma founded the not-for-profit Silk Road Project, Inc. in 1998 as "an initiative to promote multicultural artistic collaboration"6 and a "catalyst, promoting innovation and learning through the arts."

Yo-yo Ma was motivated by conductor Leonard Bernstein, who in 1973 gave a series of lectures in Harvard University titled "The Unanswered Question" touching on the universal linguistics of music. ${ }^{7}$ Bernstein himself drew on philosopher-linguist Noam Chomsky's theory of a universal grammar: a set of rules and structured constraints that all languages share, ${ }^{8}$ intricately tied in with the neuronal circuitry of the human brain. ${ }^{9}$ Bernstein expounded on that to suggest that the harmonic series is a universal truth, which is codified and structured within a universal musical syntax. Yo-yo's approach towards universality is less theoretical and more humancentric in its application, best summed-up in this quote regarding his goals for the Silk Road Project, which perhaps also offers insight into his personal mission as a musician:

"We live in a world of increasing awareness and interdependence, and I believe that music can act as a magnet to draw people together. Music is an expressive art that can reach to the very core of one's identity. By listening to and learning from the voices of an authentic musical tradition, we become increasingly able to advocate for the worlds they represent. Further, as we interact with unfamiliar musical traditions we encounter voices that are not exclusive to one community. We discover transnational voices that belong to one world."10

As Ma sought to listen and learn from unfamiliar voices and traditions, after two years of planning and fund-raising, he gathered together fifty-eight musicians and

6 (Hamilton, 2008)

7 (Bernstein et al., 2001)

8 (Chomsky, 1957)

9 (Dovey, 2015)

10 (Pincus, 2002, p. 6) 
composers of diverse ethnicities and cultures along the historic Silk Road for an experimental ten-day workshop at Tanglewood, in Massachusetts, USA where they would listen, play, interplay and co-create something new together from their distinct traditional musical styles.

The project was guardedly ambitious from its onset: 19 commissioned new works by composers from Silk Road countries mixing instruments and styles, a two-year series of concerts and broader cultural exchanges with a focus on education, including school classroom programmes and neighbourhood concerts along the route.

Prior to embarking on the Silk Road Project, there were a few key factors that led Ma to this large undertaking. His own multi-cultural background must have been instrumental. Decades earlier at a benefit concert in 1962, Bernstein had memorably introduced the 7-year-old Yo-yo to US President John F. Kennedy and the world at large as a "highly international type" and a cultural image to ponder: "a seven-yearold Chinese cellist playing old French music for his new American compatriots."

In an interview ${ }^{11}$ in 2000 , Ma likened the encounters he hoped to create via the project to the great Paris Exhibition of 1889, when a visiting Javanese gamelan orchestra was heard by Debussy ${ }^{12}$ and Ravel, bringing long-term consequences to direction and assimilated forms within French classical music. Consequently, in similar fashion, the success and acclaim of the Silk Road Project has been farreaching, resulting in six albums including a 2016 Grammy-award winner, Sing Me Home, and a Grammy-nominated feature-length documentary The Music of Strangers directed by Morgan Neville, who had won an Oscar for previous work on Twenty Feet From Stardom.

Another factor that spurred Ma was ethnomusicologist Theodore Levin's book The Hundred Thousand Fools of God: Musical Travels in Central Asia (and Queens, New York ${ }^{13}$ which related the struggles of musicians in former Soviet republics in keeping their traditions alive against severe political pressure. Ma's curiosity was piqued by the music from distant parts of the world in Queens brought along by the diaspora of diverse immigrants from the former Soviet Union (including Jewish musicians from Burkhara, an major hub along the ancient Silk Road) and also from other parts of east Asia. Ma pondered at what these waves of exodus would mean for these musicians, their music, and their impact on Western music. As a cautionary example against the globalisation of music, Argentinian composer Astor Piazzolla who lived in New York and Paris on different occasions had his music reviled for its foreign influences upon his return to Buenos Aires. ${ }^{14}$ Here, A.L. Pincus in his book Musicians with a Mission: Keeping the Classical Tradition Alive, raises this poignant

11 (Deutsch, 2000)

12 (Johnson, 2002)

13 (Levin, 1996)

14 (Pincus, 2002, p. 35) 
question: "Is it ever possible to cut yourself off from your origins?" This begs in turn its natural converse: "Is it possible for your origins to cut itself off from you?", a question I reckon many migrants (impelled or otherwise) must have felt upon revisiting their place of origin, which may have taken a different cultural path over the years or sometimes mere months away.

Anthropologist Arjun Appadurai posited in 1996 that "the central problem of today's global interactions is the tension between cultural homogenization and cultural heterogenization." 15 This tension has persisted globally in the past two decades, driven in part by the proliferation of internet, smartphone and social-media usage leading to a more homogenized globally-connected and mutually-influencing culture, balanced against increasing cultural polarization and protectionism. Almost counter-intuitively, the latter has been intensified by the heterogeneity and accessibility of myriads of cultural platforms within which drastically dissimilar cultural worlds "foster divergent sociopolitical values" and amplify the divide between groups. ${ }^{16}$

A fascinating macro-evolutionary interdisciplinary study in cultural diversity employing phylogenetic comparative methods found that the most inherited cultural traits (at least within the studied Austronesian communities) were those related to intergenerationally-acquired skills and equipment or goods required for a specialized mode of subsistence (e.g. farming and fishing). ${ }^{17}$ However, unlike such tribal or village communities which live and interact closely with each other and mostly share the same values, skills, culture and world-views, modern groups of people, especially in some urban contexts, live physically close to many others but (mostly by choice) may not share nor seek to gain an understanding of the cultures and values of, or even have a language in common with, their neighbours. This divergence has been confirmed, at least in Appadurai's technoscape in S.A. Matei's observations that the world's telecommunicative flows have become increasingly clustered along cultural and linguistic dimensions. ${ }^{18}$

I found this to be true in many pockets of New York City (particularly in Queens and Lower Manhattan) where polarized enclaves of immigrant communities coexist side by side, literally a street from each other, living and breathing the language, culture, music and grocery supplies of their original homelands, but not assimiliating into nor identifying with those of their adopted home, even after a few generations.

Thus it is against this flow of increasing social fragmentation into ethnographic, ideological or personal "echo chambers"19 that Ma, working through the limitations of this seed project ensemble, seeks to do his bit to unify humanity, at least in a

\footnotetext{
${ }^{15}$ (Appadurai, 1996)

16 (Curtis, 2017)

17 (Mace \& Jordan, 2011)

18 (Matei, 2006)

${ }^{19}$ (Samuels, 2009, p. 20)
} 
musical sense: to cross nationalistic, ethnographic or imaginary borders; to listen, learn from each other, and play in harmony.

\section{Structure}

Whetted by Boston University historian Elizabeth ten Grotenhuis' studies of the Silk Road, and its relatively recent interdisciplinary angle, Ma convened a conference in 1998 to plan the Silk Road Project as a multidisciplinary study of the music spanning the Silk route. Levin was hired as executive director, and in 1989 he travelled to Azerbaijan, Uzbekistan and Mongolia to choose composers for commissioned pieces which were planned to be recorded by the project's main funder, Sony Classical. Finally, 16 composers were selected by an advisory board, among 40 under consideration including composers from China recommended by Bright Sheng, a personal Chinese-American friend of Ma's. These composers were to write pieces for small ensembles, mixing Western and Eastern classical instruments and styles. Three other American composers with looser ties to the Silk Road were tasked to write works for the entire symphonic orchestra: Richard Danielpour of Iranian heritage, Peter Lieberson whose works were inspired by Tibetan Buddhism, and Chinese-American Tan Dun who regularly combines western and eastern elements in wide-spanning musical realms from classical Chinese opera to film and multimedia.

\section{"World Peace"}

One of the outright motivations of the Silk Road project was to foster harmony, and over its 19 years, it has brought about some notable tangible exemplars. Barely a year after their inaugural meeting and only three months after 9/11 (2001), at a time where global political tensions were high, members of the ensemble went to Aleppo, Syria to perform Islamic and western music to Muslim world leaders at their newly-restored citadel. One of the violists, Nicholas Cords recalls:

"It was a time of incredible pain and hurt; nobody knew what the future would hold... There was much sympathy for what America had just been through. My sense of what music could accomplish was enlarged."20

A few years later, in 2004, the ensemble hosted and rehearsed with six members of the Iraqi Symphony Orchestra at a workshop in New York. There was a sense of sympathy for the difficulties faced by the Iraqi musicians, as this collaborative effort of being seen playing western music on western violins put their lives at great risk with their own nation. ${ }^{21}$

\section{Bridging Gaps}

20 (Segran, 2013)

21 (Segran, 2013) 
Bringing vastly-different musical backgrounds together in this ensemble can be seen as a microcosm for global cooperation as a shared vocabulary has to be developed to allow the musicians to communicate effectively, and compromises have to be found for gaps that exist in each others' backgrounds. For example, members of the group have unique forms of musical notation, and some may not even have any notation at all, such was the case for tabla (a pair of non-identical Hindustani drums) player Sandeep Das, who when encouraged to compose a piece for the group, was asked to "just bring his thoughts to the rehearsal", which he did, wholly in his mind - and it led to his first Silk Road composition.

Through their musical interactions, Silk Road musicians have found disparate similarities and unexpected kinship between their respective cultures. Whilst improvising with Iranian kamancheh (spike fiddle) player Kayhan Kalhor, Das quipped that "playing with Kayhan for the first time felt like playing with a long-lost cousin" despite the fact that he was playing a raga (lit. coloring, dyeing. An array of motifs within melodic structures which is a central feature of north Indian classical music with no direct parallels in European music) and Kalhor was playing in Persian mode, ${ }^{22}$ a complex musical system of seven "royal modes" called Xosrovani, 30 modulation forms and 360 dastan melodies, corresponding to the days of weeks, months and years. On his musical collaboration with Das and sitar player Ustad Shujaat Husain Khan, another collaborator of the ensemble, Kalhor said:

“It's not Persian music, it's not Indian music. It's something that didn't exist before. It has some musical values to offer to the listener, some meaningful values."

\section{Musical Instrument Diffusion}

The Silk Road Ensemble uses many instruments that have been commonly played across the region where there has been distinct cultural diffusion over the millennia, leading to these instruments being adapted and modified as their usage "travelled" geographically. This is reflected too in the etymology of some of their names, which hints at their origin.

For example, in Persia, the word for "string" is tar, which is also the name of a fretted plucked instrument with six parallel strings arranged as three courses (close identically-tuned pairs) and a "flying" bass string an octave lower than the middle course. Precursors for this include the ektar (lit. one string), dutar (two strings) and setar (three strings). The tar made its way to Spain where it was named the guittara, which started out having four single strings, but eventually two more were added. Meanwhile the setar made its way east to India where it featured prominently in Hindustani music as the sitar, and took on a life of its own and now has six or seven playable strings and up to 14 sympathetic strings which provide resonance.

22 (Farmer, 1926) 
In parallel, the Persian tanbur a distinct long and narrow-necked string instrument with a gourd-like body moved into Central Asia (retaining its name but having slightly differing forms in Afghanistan, Tajikistan and Uzbekistan), Xinjiang (tembor), Arabia (tunbur), Turkey (tambur, where its body became round), India (tanpura), Pakistan (tanburag), Ukraine (bandura), Kazakhstan (dombra), Russia (domra), Eastern Europe (tamburica), and Greece (tambouras).

A completely wooden-bodied, broader-necked version of this evolved into the modern lute, which probably started in Mesopotamia (since the third millennium BCE), ${ }^{23}$ Persia (barbad or barbud), Arabia (oud or $u d$, lit. wood), ancient Greece (pandura or pandoura), China (pipa), and all the way to Japan (biwa). ${ }^{24}$ Far more recently, the migration of instruments has also occurred from east to west, for example, the Japanese Nagoya harp (taishogoto) invented in 1912 based on the key mechanism of the typewriter, became localised in India (bulbul tarang or, confusingly, "banjo", which is also the English name of a completely different plucked instrument played by $17^{\text {th }}$ century West African slaves in the Caribbean), Iran (benjo or binjo), ${ }^{25}$ East Africa (taishokoto) and Germany (akkordolia).

Now onto the woodwinds, the sorna (lit. strong flute, a double reeded horn) was an ancient Persian ${ }^{26}$ instrument that migrated eastward to India (shahna), China (suona), and westward to the Middle East (mizmar or zamour), Turkey (zurna), Croatia (sopila), Iberia (shawm) and North Africa (rhaita or ghaita). The term gaita is used in northern Iberia to exclusively refer to bagpipes, which are also reed instruments, but enclosed, and played by squeezing a reservoir of air (the "bag").

\section{Featured Instruments and Musicians}

For the scope of this project it would be difficult to give a detailed analysis of all performing musicians of the rather fluid Silk Road Ensemble which number around sixty, so I will only highlight a few key artists and their distinct instruments, a choice aided in part by Morgan Neville's selection in his documentary. The most striking stories come from the ancient Near East (Western Asia, also what is affectionately termed the "Cradle of Civilization"), where areas ranging from Iran to Syria have been ravaged by war as they have been contested and overrun by various empires for millennia. ${ }^{27}$ In the midst of this, people and cultures have survived and even thrived despite the adversity of being decimated by such conflicts.

Kinan Azmeh, a Silk Road composer and clarinettist from Damascus, weighed his role and purpose as a musician after the 2011 Syrian revolution ravaged his people.

\footnotetext{
23 (McKinnon \& Anderson)

24 (Nassehpour, 2017)

25 (Nassehpour, 2017)

26 (Nassehpour, 2017)

27 ("Imperial History of the Middle East," 2017)
} 
Due to the external situation and internal conflict, he even stopped composing for a year but came to this purposeful conclusion later on:

"For the past six years, I've realized the limitation of art. Sometimes I look at my clarinet and I know that it can never stop a bullet, it cannot feed the hungry, it cannot free a political prisoner and it cannot rebuild a destroyed home. However, I think making music is an act of freedom and inspiration, and it can affect people and motivate them to be proactive." 28

Azmeh brought this hope of freedom into his stirring melodious, and at times cacophonous, improv-friendly composition Wedding, drawn from his observations of loud village weddings on a trip to the Syrian countryside (presumably after the armed conflict had already begun). He quips:

“As I see it, I think it's quite inspiring to see how there are Syrians who manage to fall in love, under the falling bombs and all these bullets. Now we are using the piece as a little hope at the end of the concert."

Meanwhile, from the opposite end of the Middle East and bordering Central Asia, Kurdish kamancheh virtuoso Kalhor Kayhan (introduced earlier) was impelled by unfavourable the political situation to leave his home of Tehran, Iran after its Islamic Revolution in 1979. He recalls to CNN in 1999:

"Well-known musicians who left Iran at the time couldn't actually train young people any more, and they had to leave. The other very wonderful aspect of this was that Persian music ... was introduced to other societies and cultures. So that's actually the reason I'm sitting here now."

In a 2008 collaboration with four other founding Silk Road Ensemble musicians who later became the Brooklyn Rider string quartet, Kayhan produced an album Silent City with its titular centrepiece a stirring half-hour elegy to the 1988 massacre at the Kurdish city of Halabja by Iraqi chemical bombs which killed up to 7,000 civilians and brought about prolonged damage to the rest through increased rates of cancer, miscarriages and congenital-defects years later. ${ }^{29}$

I've replayed the piece numerous times over the course of this project, and each time it lends something different. It starts out quietly droning and dissonant as the kamancheh, violins, viola and cello interplay to paint a haunting desolate landscape. This, I learnt later, comes from the deliberate initial two group improvisation sections where Kayhan explains in album's liner notes, "the compositional style in the first sections of the piece is unusual and based on signs. In this style, each musician performs his own interpretation of the signs." However, these improvised moments are based on certain non-explicit rules based on the Iranian mode

28 ("Interview with Kinan Azmeh," 2017)

${ }^{29}$ (Muir, 2002) 
dastgah-e shur, which Kayhan chose to enable flexible spontaneous modulation (due to its similarity with A minor) and also give a sense of intercultural universality:

"This scale exists [in] China, [in] the Muslim-settled areas of China, which have been under the influence of Iranian music, to North Africa. It exists everywhere. ... With a slight change in its second degree, it can sound like Western music and if you move your finger forward [on kamancheh] and play the second degree sharper, it becomes our own shur. If you play it even sharper, it changes to one of the Kurdish maqams." 30

After a short (also improvised) kamancheh soliloquy section, the piece moves to a hopeful, more harmonious finale with a joyful dance motif. This final nonimprovised segment, composed by Kalhor and fellow Silk Road Ensemble composer Lev 'Ljova' Zhurbin, symbolises the resolution of conflict through its cheerful transparent harmony.

I could (and probably should) have gone on highlighting other exciting members and musical styles of the Ensemble: the bubbly Chinese pipa player Wu Man, who as a child was coerced by her parents to study music (instead of dance, which she had preferred) as a means of escaping the country during the Chinese Cultural Revolution, choosing specifically for her the pipa because they thought "the shape of the pipa [was] very elegant for a girl to hold"; charismatic Galician gaita (bagpipe) player Cristina Pato, who along with Japanese shakuhachi (edge-blown flute) player Kojiro Umezaki pieced together "Vojo", an Esperanto-inspired composition that connects the vastly-differing woodwind styles at the terminal ends of the Silk Road: Galicia (Spain) and Okinawa (Japan). There are but a small handful of the many stories that exist within the ensemble and those who work alongside it. As an example, the Aga Khan Foundation, one of the project's key sponsors, is a not-forprofit international development agency seeking to provide long term solutions for poverty, hunger, illiteracy and health in the poorest regions of South/Central Asia, Africa and the Middle East, and regularly engages the Silk Road team in educational and cultural programmes in those regions.

\section{Concluding Remarks}

Certainly, there are key limitations to the scope of Ma's aims and the execution of his ideas: the omission of the various indigenous groups within the other continents (or even other parts of Asia), for instance; the choice of his, often-already wellestablished composers and musicians; the link to the Sony label and large corporate sponsorships to be more certain of commercial success.

Tamara Chin, a comparative literature professor and critic of idealized perceptions of the Silk Road, pointed out that different civilizations regarded its history and origin differently according to how it suited them. In contrast to China's view of the

30 (Rostami, 2017) 
road beginning with the journey of Zhang Qian in the second century BCE, she pointed out how the very term was only "invented" in 1877 by German geographer Baron Ferdinand von Richthofen, who then coined it "die Seidenstrasse" (lit. silk road). Contrasting the sometimes historically-divergent perspectives (and even maps!) of the road's span and scope from von Richthofen, Ptolemy, geologists, Europe, China and Central Asia, she lumps Yo-yo Ma's efforts as simply being an invented "model of idealized exchange". ${ }^{31}$

Methaphorical or otherwise, Ma's reinvoking of the world-bridging Silk Road struck me deeply personally when I attended in late-July last year with a couple of friends, the Canberra premiere of The Music of Strangers at Palace Electric cinemas, where my spouse's cello teacher was to perform with another local musician at the after party. Being a fan of film and Ma's classical cello renditions, I probably would've seen the movie at some point anyway, but there, watching Morgan Neville bring to life the inspiring back story and motivations behind Ma's global efforts, seeing afterwards the multi-ethnic attendees of all ages chatting voraciously at that opening gala of the Stronger Than Fiction documentary festival against the backdrop of live improvised cello and djembe - musical instruments and styles supposedly from different worlds - I was awestruck, that for a few hours in chilly Canberra, the warmth of humanity could travel across cultures, musical styles, and even celluloid to show that in our diversity (and increasing social fragmentation) there could yet be communication, musical and cultural appreciation, and even harmony - not simply as defined by Bach and western classical music, but a living dynamic unscripted improvisation of microtones and microcultures.

Perhaps these efforts are simply transient notes in the clamorous bazaar of human interaction. Pure, hopeful tones that overlay, interplay, give each other room, to breathe, to be heard.

In the film's official trailer Ma humbly and sincerely quips: “I'm always trying to figure out where I fit in the world, which I think is something that I share with seven billion other people."

This Silk Road Project, which started as a personal creative experiment for Ma, has gone on to affect others positively: from the initial 60 bleary-eyed musicians fresh off the bus at Tanglewood, to the innumerable people (myself included) who have heard the music and story of this nearly two-decade long project. This initiative has kept reinventing itself (during the course of my writing over the past few weeks [in Nov 2017] its name has gone from the Silk Road Project, Inc. to simply Silkroad) and has gotten so big that, perhaps in preparation of their twentieth anniversary, Ma has very recently handed over the reins of artistic direction of the Ensemble to not one but three other members within the team. ${ }^{32}$

31 (Chin, 2013)

32 (Anderson, 2017) 
In biology, the key measure of "fitness" (as referred to in the Darwinian concept "survival of the fittest") of a living species is not how well a single individual does (however that's measured), nor how long it lives, and not even how many offspring ("copies" of itself) it leaves behind, but how many of its offspring's offspring (grandchildren) are viable. It is this continuity that determines the survival and thriving of the species.

Ma's revolutionary approach to cultural tradition is reflected in this quote: "the idea of culture is not so much to preserve tradition, but to keep things alive and to evolve things." Thus, simply put, the coming together of ideas and traditions, ensure their long-term survival through constant change and adaptation. By stepping down to let his brain- (and probably, heart-) child evolve on its own, Ma is taking a brave new step of trust that this cross-cultural musical revolution he has sparked will take on a life, form and direction of its own. Of its fitness and impact on musical history, only time will tell. But to those like me who've heard and been moved, it has been an inspiration to step out of my self-imposed professional, cultural and ethnographic boundaries, and do more. 
Bibliography:

Anderson, A. (2017). Yo-Yo Ma hands over the reins of Silk Road Ensemble. Retrieved from http://www.internationalartsmanager.com/news/music/yoyo-ma-hands-over-the-reins-of-silk-road-ensemble.html

Appadurai, A. (1996). Modernity At Large: Cultural Dimensions of Globalization: University of Minnesota Press.

Bernstein, L., Smith, D., Mozart, W. A., Beethoven, L. v., Berlioz, H., Wagner, R., ... Wiener Philharmoniker. (2001). The unanswered question six talks at Harvard by Leonard Bernstein [6 videodiscs (793 min.)]. West Long Branch, NJ: Kultur.

Chin, T. (2013). The Invention of the Silk Road, 1877. Critical Inquiry, 40(1), 194219. Retrieved from http://www.journals.uchicago.edu/doi/abs/10.1086/673232. doi:10.1086/673232

Chomsky, N. (1957). Syntactic Structures. The Hague: Mouton \& Company.

Curtis, J. (2017). A Fake America: Cultural Fragmentation and Polarization. Harvard Political Review. Retrieved from http://harvardpolitics.com/online/fakeamerica-cultural-fragmentation-polarization/

Deutsch, R. W. (2000). Yo-Yo Ma Mines Global Musical Culture. Retrieved from http://www.fastlanefilms.com/sonic/yo\%20yo\%20ma.html

Dovey, D. (2015). Noam Chomsky's Theory Of Universal Grammar Is Right; It's Hardwired Into Our Brains. Retrieved from http://www.medicaldaily.com/noam-chomskys-theory-universal-grammarright-its-hardwired-our-brains-364236

Farmer, H. G. (1926). The Old Persian Musical Modes. Journal of the Royal Asiatic Society of Great Britain \& Ireland, 58(1), 93-95. Retrieved from https://www.cambridge.org/core/article/old-persian-musicalmodes/59735C5C8521B2C6377DD65373A99F4D. doi:10.1017/S0035869X00055593

Hamilton, G. (2008). Follow the mellow Silk Road with Yo-Yo and his cello. Independent. Retrieved from https://www.independent.ie/entertainment/music/follow-the-mellow-silkroad-with-yoyo-and-his-cello-26471326.html

Hays, J. (2017). Silk Road During the Han Dynasty (206 B.C.- A.D. 220): Wu Di, Romans, Sogdians and Parthians. Facts and Details. Retrieved from http://factsanddetails.com/china/cat2/sub90/entry-5440.html\#chapter-1

Imperial History of the Middle East. (2017, November 14). [Shockwave Flash] Retrieved from http://www.mapsofwar.com/ind/imperial-history.html

Interview with Kinan Azmeh. (2017). [Interview]. Retrieved from http://www.hamburg.com/elbphilharmonie/kinan-azmeh/

Johnson, H. (2002). Balinese music, tourism and globalisation: inventing traditions within and across cultures. New Zealand Journal of Asian Studies, 4(2), 8-32.

Levin, T. C. (1996). The Hundred Thousand Fools of God: Musical Travels in Central Asia (and Queens, New York): Indiana University Press.

Levitt, T. (1960). Marketing myopia. Harvard Business Review(July-August), p.45-56. 
Mace, R., \& Jordan, F. M. (2011). Macro-evolutionary studies of cultural diversity: a review of empirical studies of cultural transmission and cultural adaptation. Philosophical Transactions of the Royal Society B: Biological Sciences, 366, 402-411.

Matei, S. A. (2006). Globalization and heterogenization: Cultural and civilizational clustering in telecommunicative space (1989-1999). Telematics and Informatics, 23(4), 316-331. Retrieved from http://www.sciencedirect.com/science/article/pii/S0736585305000456.

McKinnon, J. W., \& Anderson, R. Ancient lutes. Grove Music Online. Retrieved from http://www.oxfordmusiconline.com/subscriber/article/grove/music/4007 4pg2\#S40074.2

Muir, J. (2002). Kurds look back with fear. BBC News: Middle East. Retrieved from http://news.bbc.co.uk/2/hi/middle east/2138447.stm

Nassehpour, N. (2017). Impact of Iranian Music on Other Cultures and Vice Versa. Iran Chamber Society: Music of Iran. Retrieved from http://www.iranchamber.com/music/articles/iranian music other culture. php

Pincus, A. L. (2002). Musicians with a Mission: Keeping the Classical Tradition Alive: Northeastern University Press.

Qian, S. (1993). Records of the grand historian : Han dynasty (B. Watson, Trans.). Hong Kong ; New York: Renditions-Columbia University Press.

Rostami, M. (2017). Silent City: A Commemoration of Halabja's Tragedy. Music and Politics, 11(1). Retrieved from http://dx.doi.org/10.3998/mp.9460447.0011.105. doi:10.3998/mp.9460447.0011.105

Sadler, M. (1930). Towards a New Education: A Record and Synthesis of the Discussions on the New Psychology and the Curriculum at the Fifth World Conference on the New Education Fellowship Held at Elsinore, Denmark, in August 1929 (W. Boyd \& M. M. Mackenzie Eds.). Helsingor, Denmark: A.A. Knopf.

Samuels, R. (2009). New Media, Cultural Studies, and Critical Theory after Postmodernism: Automodernity from Zizek to Laclau: Palgrave Macmillan US.

Segran, E. (2013). A Yo-Yo Ma Project Brings Together Musicians From Warring Nations. The Atlantic. Retrieved from http://www.theatlantic.com/international/archive/2013/10/A-Yo-Yo-MaProject-Brings-Together-Musicians-From-Warring-Nations/280458/

Twitchett, D., Fairbank, J. K., \& Loewe, M. (1978). The Cambridge History of China: Volume 1, The Ch'in and Han Empires, 221 BC-AD 220 (Vol. 1): Cambridge University Press. 